\title{
THE FACTORS CAUSING ENGLISH SPEAKING ANXIETY ON NON-ENGLISH MAJOR ACADEMICS WHILE USING ENGLISH AS A MEDIUM OF INSTRUCTION
}

\author{
Mustafa Yildiz \\ (mustafayildiz@sinop.edu.tr) \\ Sinop University \\ Korucuk Mah. Trafo Sok. 15 Temmuz Yerleşkesi No:36 57000 Sinop, Turkey
}

\begin{abstract}
This qualitative study aims to reveal the factors causing English speaking anxiety on non-English major academics while using English as a medium of instruction. Eight non-English major academics with the experience of teaching in English participated in the present research. Semi-structured oneon-one interviews and e-mail interviews, which are qualitative data collection techniques, were used as data collection tools. Manual coding of qualitative data that requires in-depth reading of the transcripts and assigning codes and themes was used to interpret the data. The results reveal the situations that provoke speaking anxiety among the non-English major academics. They can be grouped under five main themes: academics' English proficiency, academics' selfevaluation, learner behaviors, learner inadequacies, and cultural differences. These five main themes can also be confined to individual factors, learner factors, and cultural factors. It can therefore be assumed that the factors causing English speaking anxiety on non-English major academics have to be considered within multidimensional aspects rather than simply originating from academics themselves.
\end{abstract}

Keywords: academics' English speaking anxiety, anxiety provoking factors, cultural factors, EMI, individual factors, learner factors, selfevaluation

DOI: http://dx.doi.org/10.15639/teflinjournal.v32i2/389-412

Speaking English is a challenging activity that almost every language user has difficulty in coping with in different circumstances. In academic settings, there 
is an increasing demand for academics of different majors to be able to use English as a medium of instruction. International mobility programs for academics are one of the reasons for improving productive language skills to be effective throughout the teaching process abroad. However, previous research has shown that there exist a lot of reasons that cause trouble for academics while they are using English as a medium of instruction. The fear of negative evaluation, making mistakes, negative perceptions, even low proficiency in the target language are some of the factors that inhibit oral production (Öztürk \& Gürbüz, 2014; Riasati, 2011; Shabani, 2012; Tsiplakides $\&$ Keramida, 2009). These anxiety provoking factors directly affect one's oral performance in the target language.

The purpose of this qualitative study was to explore the factors causing English speaking anxiety on non-English major academics. A wide variety of research on the effects of anxiety on language achievement have focused on the topics from more general foreign language learner anxiety to more specific foreign language speaking, writing, listening, and reading anxiety. All four language skills and their relationship with anxiety are discussed separately in literature; however, a great majority of previous studies discuss the general foreign language learner anxiety (Botes et al., 2020; Castillejo, 2019; Cui, 2011; Dolean, 2016; Ferdous, 2012; Jin et al., 2020; Riasati, 2011; Toth, 2011). Additionally, even though there are innumerable studies related to anxiety and its effects on college and undergraduate level students (Çağatay, 2015; Han et al., 2016; Kao \& Craigie, 2013; Lu \& Liu, 2011; Lucas et al., 2011; Matsuda \& Gobel, 2004; Semmar, 2010; Shabani, 2012; Williams \& Andrade, 2008; Yentürk \& Dağdeviren-Kırmızı, 2020), very few studies related to anxiety experienced by teachers and lecturers exist (English teachers teaching at secondary schools in Klanrit \& Sroinam, 2012; lecturers of English teaching beginner-level learners in Kongchan \& Singhasiri, 2008; non-English major academics teaching undergraduate level in Han et al., 2020; EFL teachers teaching learners with various language proficiency in Kralova \& Tirpakova, 2019). From this aspect, the present study will attempt to fill a research gap in the existing literature by revealing the factors causing English speaking anxiety on non-English major academics. The findings will add to a growing body of literature on anxiety by providing insights into whether the factors causing anxiety on non-English major academics show similarity with those on language learners and whether the factors are caused by the academics 
Yildiz, Factors Causing English Speaking Anxiety on Non-English Major 391

themselves or there are other reasons beyond their control. The following research question was therefore raised to reveal the factors that cause English speaking anxiety on non-English major academics: What are the sources of English speaking anxiety that non-English major academics experience while using English as a medium of instruction (EMI)?

\section{LITERATURE REVIEW}

\section{Definition and Types of Anxiety}

How anxiety affects learners' achievement is a mostly investigated subject in literature. Anxiety is one of the most important factors influencing learners' performance in second language classrooms. Learners' emotional tension while learning a foreign language has an effect on their accomplishment level in four language skills. "Language anxiety can be defined as the feeling of tension and apprehension specifically associated with second language contexts, including speaking, listening, and learning" (MacIntyre \& Gardner, 1994, p. 284). Throughout foreign language learning process, some learners do not feel comfortable and experience anxiety because of various reasons.

Psychologists divide anxiety into three categories as trait anxiety, state anxiety, and situation-specific anxiety (Horwitz et al., 1986; Spielberger, 1972). Woodrow (2006) mentions the trait anxiety as "a relatively stable personality trait" (p. 309). People who are trait anxious are prone to experience anxiety in various situations; and living as anxious becomes a lifestyle for them. On the other hand, state anxiety is "the transient, moment-to-moment experience of anxiety as an emotional reaction to the current situation" (Dörnyei, 2005, p. 198). The situation causing state anxiety is temporary for state anxious people. It varies by the situation that the individuals encounter with. State anxious people are not predisposed to experiencing anxiety in all situations like the trait anxious people do. The last type of anxiety is situation-specific anxiety (Horwitz et al., 1986). MacIntyre and Gardner (1991) describe the situationspecific anxiety as a trait anxiety limited to a specific situation in which "respondents are tested for their anxiety reactions in a well-defined situation such as public speaking, writing examinations, performing math, or participating in French class" (p. 90). Language learning situation in classroom environment gives rise to situation-specific anxiety. 


\section{Anxiety on Teachers and Teacher Candidates}

Kongchan and Singhasiri (2008) attempted to investigate whether teachers really experience anxiety while teaching English through English to low proficient students. The results show that none of these teachers feel anxiety. Even though they worry that learners do not understand them because of teaching English through English, they overcome this problem by using coping strategies. Contrarily, in a similar study done by Yoon (2012) in which the data is gathered in the same way as in Kongchan and Singhasiri (2008), the results indicate that participants feel lack of confidence about English and they have problems in teaching through the target language.

In addition to teachers' lack of confidence about English, students' attitudes towards studying English, teachers' language proficiency, teaching and learning management are the further factors causing anxiety on teachers found in Klanrit and Sroinam (2012). Similarly, almost half of the participants in Han et al.'s (2020) study experience anxiety in international academic meetings due to their low language proficiency. Some additional variables such as age, the time during which EFL teachers live in an English-spoken country and the time they spent for teaching and learning English are investigated in Kralova and Tirpakova (2019) to see their relationship with non-native EFL teachers' English speaking anxiety. They find that as the age of the participants increases, their speaking anxiety also increases. As the age decreases, the speaking anxiety levels also decrease. Further results indicate that the participants are not happy with their vocabulary knowledge and pronunciation skills. In addition, word recalling is surprisingly the most problematic issue for young teachers.

All in all, past research indicates that there is a wide variety of factors causing anxiety among teachers and teacher candidates. These factors can be grouped under two headings as self-based and learner-based reasons. On the one hand, feeling lack of confidence in language skills and having problems in using English as a medium of instruction appear to be self-based reasons arisen from teachers and teacher candidates. On the other hand, learners' attitudes towards English lessons can be the learner-based reason that gives rise to anxiety on teachers. 
Yildiz, Factors Causing English Speaking Anxiety on Non-English Major 393

\section{METHOD}

Qualitative research design is chosen for the present study to gain a deep insight into the phenomenon of English speaking anxiety from the point of view of academics. Maykut and Morehouse (2005) assert that "research studies that are qualitative are designed to discover what can be learned about some phenomenon of interest, particularly social phenomena where people are the participants" (p. 39). Qualitative methods give participants an opportunity to put their experiences and their viewpoints on a selected issue into words. The present study enabled academics of non-English majors, who had attended international mobility programs and had had the chance to use English as a medium of instruction (EMI), to share their teaching experiences.

\section{Participants}

Contrary to quantitative sample building in which participants are selected randomly, the participants of the present study were incorporated into the research intentionally to explore the sources of anxiety they experience while lecturing in English. In this study, the researcher applied purposive sampling technique. According to Maykut and Morehouse (2005), "qualitative researchers set out to build a sample that includes people selected with a different goal in mind: gaining deep understanding of some phenomenon experienced by a carefully selected group of people" (p. 51). Homogeneous sampling method was utilized to create a group of academics who possessed similar characteristics and traits. The present study included participants who got at least 'B' grade from national English proficiency exams, which equals to B2 or above on the CEFR scale, and who had benefited from international mobility programs and had experienced lecturing in English. The participants were faculty members with non-English majors. They taught at university undergraduate level and their students were of different English proficiency levels. The learners taught by the participants were mostly non-native speakers of English, with some native speakers. Some academics also taught at the graduate level. Table 1 summarizes the demographic information of all the participants.

Eight academics, three of whom were females, who had had the chance to use English as a medium of instruction (EMI) were the participants of the present study. Six participants held a $\mathrm{PhD}$ degree, three of whom completed 
their $\mathrm{PhD}$ education in countries where English is the official language. Five participants were between the ages of 30-44, and three others were between the ages of 45-60.

Table 1. Demographic Information About Participants

\begin{tabular}{|c|c|c|l|l|}
\hline Participants & Gender & Age & Degree & Field \\
\hline A & M & $45-60$ & PhD from the UK & Physical Sciences \\
\hline B & M & $30-44$ & Master of Arts & Social Sciences \\
\hline C & M & $45-60$ & Master of Arts & Physical Sciences \\
\hline D & F & $30-44$ & PhD & Physical Sciences \\
\hline E & M & $30-44$ & PhD & Physical Sciences \\
\hline F & F & $45-60$ & PhD & Physical Sciences \\
\hline G & M & $30-44$ & PhD from the US & Educational Sciences \\
\hline H & F & $30-44$ & PhD from the US & Educational Sciences \\
\hline
\end{tabular}

\section{Procedure}

While one-on-one semi-structured interviews were conducted with academics working in close faculties with easy access, semi-structured e-mail interviews were conducted with the ones working in remote faculties out of the city. After the interviews were completed, some participants, regardless of their workplace, were contacted via e-mail interviews for further clarification when necessary. Interview is the most appropriate data collection tool suitable for the present research as the research question investigates the participants' past experiences; and the researcher does not have the chance to observe the participants during their teaching process. Before the interviews were conducted, the interviewees were kindly requested to sign a consent form informing them about the purpose of the study, their rights throughout the data collection process, and approximate time required for completing the interviews. Interviews taking place in the office of each academic were recorded and transcribed for the analysis of data.

An interview protocol was used to guide the interviews. Creswell (2012) mentions the interview protocol as "a form designed by the researcher that contains instructions for the process of the interview, the questions to be asked, and space to take notes of responses from the interviewee" (p. 225). This protocol, providing uninterrupted flow of the interview, is a sort of organizer 
which consists of questions to be asked during the interviews and of details about interviewees and the study.

Each of the interviews was conducted one on one and each interviewee was asked open-ended questions exploring factors causing anxiety during their teaching process in English. Creswell (2012) underlines that open-ended questions give the interviewees the chance of giving open-ended responses which are non-forced and non-orientated by the researcher avoiding asking leading questions which may direct the participants to answer in favor of or against the expected results.

\section{Data Analysis}

After the researcher collected the raw qualitative data through interviews, the data analysis process began with the transcription of the audio-taped interviews. Each interview was transcribed by converting the audio-taped materials into the written form to analyze the collected data easily. Because of preferring hand analysis of qualitative data, the researcher took attention to leave extra space on paper for writing memos during the transcription. Completing the transcription of audio-taped materials, the researcher read the written text repeatedly in order to get a general sense and to see if further data was needed. Coding the data was the next step in the process of qualitative data analysis. Creswell (2012) mentions the coding as "a process of segmenting and labelling text to form descriptions and broad themes in the data" (p. 243). Firstly, the researcher determined the text segments which are a set of similar expressions stated by the interviewees and tried to code them with terms taken from the literature relevant to the research question. During this process, specific quotes were determined from the interviewees to promote the codes.

Completing coding the whole text, the researcher reviewed the similar codes and grouped them to get minimum themes as much as possible because the aim of the study is to explore the subject in detail and to get an in-depth understanding of the factors causing anxiety on non-English major academics. Instead of reporting superficially with a bunch of themes at the end of the research, providing detailed discussion for a small number of themes is more feasible for qualitative data analysis. In the section of reporting findings, the researcher summarized the themes as findings one-by-one in detail.

The researcher and a colleague with an MA degree in ELT coded the whole data independently. Inter-coder reliability was calculated in order to test 
if the coding of the data showed adequate agreement. Miles and Huberman (1994, p. 64) suggest the following formula to measure consistency between two coders.

$$
\text { reliability }=\frac{\text { number of agreements }}{\text { total number of agreements }+ \text { disagreements }}
$$

Figure 1. Formula for Inter-Coder Reliability

The two raters reached $80 \%$ agreement in the coding of the data, which reflects a high-level of consistency between coders.

\section{FINDINGS AND DISCUSSION}

\section{Findings}

With regard to English speaking proficiency, the participants describe themselves as good or very good at speaking English. One of them refrains from revealing more details about English speaking skills. The participants' mood profiles while teaching in English differ considerably. Participant A states that:

"I have built an extreme self-confidence while speaking English as a consequence of my academic background and mastery in speaking English."

According to Participant A, teaching in English is an extremely appealing activity. On the other hand, Participant B, refraining from giving details about his English speaking proficiency, describes himself as flurried, anxious, and occasionally stressful. The rest of the participants express that they are mostly enthusiastic about teaching in English; and their mood profile is usually the same while teaching both in their first language and English.

Table 2 summarizes the codes and themes as findings of the present research concerning the factors that cause English speaking anxiety among the participants. It shows a total of five themes and 12 more specific codes under the themes were identified in the data analysis as the anxiety-provoking situations. These can be categorized into three different factors: individual, learner and cultural factors. Two themes were of individual factors: academics' English proficiency and academics' self-evaluation; two others were of learner 
Yildiz, Factors Causing English Speaking Anxiety on Non-English Major 397

factors: learner behaviors and learner inadequacies; and the other theme was of cultural factors: cultural differences.

Table 2. Summary of the Results

\begin{tabular}{|c|c|c|}
\hline Individual Factors & Learner Factors & Cultural Factors \\
\hline $\begin{array}{l}\text { English Proficiency } \\
\text { - } \quad \text { failing to recall correct } \\
\text { lexical items } \\
\text { - } \quad \text { deficiency in lecturing } \\
\text { in English } \\
\text { - } \quad \text { dealing with } \\
\text { extracurricular topics } \\
\text { - } \quad \text { facing a problem with } \\
\text { answering students' } \\
\text { questions } \\
\text { being unable to } \\
\text { understand what is } \\
\text { uttered by the learners }\end{array}$ & $\begin{array}{l}\text { Learner Behaviors } \\
\text { - } \text { the learners with an } \\
\text { impassive look on their } \\
\text { face } \\
\text { - learners' lack of interest } \\
\text { to the lesson }\end{array}$ & $\begin{array}{l}\text { Cultural Differences } \\
\text { - } \quad \text { failing to } \\
\text { comprehend } \\
\text { gestures and } \\
\text { cultural jokes }\end{array}$ \\
\hline $\begin{array}{l}\text { Academics'Self Evaluation } \\
\text { - } \quad \text { academics' over- } \\
\text { monitoring their own } \\
\text { speech } \\
\text { - } \quad \text { the fear of negative } \\
\quad \text { evaluation }\end{array}$ & $\begin{array}{l}\text { Learner Inadequacies } \\
\text { - } \quad \text { learners' lack of an } \\
\text { acceptable level of } \\
\text { proficiency in English } \\
\text { - } \quad \begin{array}{l}\text { learners' academic } \\
\text { inadequacy }\end{array} \\
\end{array}$ & \\
\hline
\end{tabular}

\section{Individual Factors}

The factors arising from the academics themselves and causing anxiety are considered to be individual factors which will be discussed under two subheadings, namely, English proficiency and academics' self-evaluation.

\section{English Proficiency}

Some anxiety-provoking situations arise from the lack of English proficiency which is the most frequently reported reason for the English speaking anxiety of the non-English major academics participating in this study. This is elaborated in the following sections. 
398 TEFLIN Journal, Volume 32, Number 2, July 2021

\section{Failing to Recall Correct Lexical Items}

Failing to recall correct lexical items appears as one of the most striking factors the participants commonly mention. The fear of being unable to provide the permanence of the communication due to the limited vocabulary knowledge makes them extremely anxious. They believe that the lesson is interrupted when they have some problems with recalling the exact words, which breaks their concentration. The loss of concentration causes the participants to have some problems with the flow of the lesson. Some preplanned course contents face the risk of being forgotten. The participants try to compensate for the unknown vocabulary items by using more familiar words. Participant $\mathrm{G}$ states that:

"As the words and terms that I have misused or I think I have misused cause displeasure on the learners' face, I feel myself extremely anxious. In these cases when I am not able to recall the exact words, even if I try to explain what I am

trying to do indirectly, I feel that the learners do not find my answer satisfactory."

The answer from participant $G$ suggests that $s /$ he unconsciously and unsuccessfully tries to use circumlocution techniques when $\mathrm{s} /$ he cannot recall the most appropriate words; however, as a result, it seems that the reactions participant $\mathrm{G}$ gets from the students do not satisfy him/her.

\section{Deficiency in Lecturing in English Because of Low English Proficiency}

Deficiency in lecturing in English because of low English proficiency is another factor causing anxiety on academics. Some participants underline that feeling some deficiencies in lecturing both impairs the integrity of the lesson and distracts learners' attention. This kind of situation makes the academics feel anxious, increasing the pressure on them that complicates the climate of tension even further. Participant $G$ states that:

"teaching to undergraduate learners is quite delighting activity. However, in graduate classes, I have encountered with lots of problematic cases in which some students as native speakers of English objected to taking lessons from a nonnative speaker of English. Teaching to native speakers of English is really a challenging and anxiety-provoking activity for a lecturer who is a non-native speaker of English." 
Yildiz, Factors Causing English Speaking Anxiety on Non-English Major 399

Participant B expresses that:

"Teaching students who are native speakers of English, having native accent and fluent in English is a kind of anxiety-provoking experience for me. In the absence of these students, I feel really comfortable. However, their availability in classroom puts me to inconvenience. I feel as if I had to be perfect especially in pronunciation and as fluent as a native English speaker. I feel as if I were before the jury and they judge my English skills."

The excerpts from the answers provided by participants G and B illustrate that the learners with English as their native language trigger the academics' English speaking anxiety. Surprisingly, even the academics with a $\mathrm{PhD}$ degree from the US feel anxious while teaching to native speakers of English by means of English as a medium of instruction. It can be inferred that even living for a while in a country where English is spoken as a native language cannot prevent non-English major academics from feeling anxious when teaching the native speakers of the target language.

\section{Dealing with Extracurricular Topics}

Dealing with extracurricular topics is another challenging situation. The participants feel exceedingly nervous as they have to talk about unexpected issues, especially irrelevant to classwork. The participants, especially the members of the departments from physical sciences, underline that they complete their undergraduate and graduate education in English. So, they are closely acquainted with the English terms of their academic fields and happy with teaching in English. However, they experience a complete lack of maintaining the fluency when they have to talk about daily life. These situations make them feel the tension. Participant E states that:

"I confine these extracurricular daily examples to the minimum and benefit from visual materials and drawing on the board, if possible."

Participant G, a member of a department from Social Sciences as well, states that:

"Going beyond the scope of daily lesson plan may cause an unexpected tension while teaching in English as a foreign language. I wish I had had a chance to use my native language, which may lead to a more sophisticated and productive classroom environment." 
Participant G's statement implies that the use of mother tongue while teaching has a chance to make a positive difference. The participants believe that if they had the chance of using their mother tongue during the class, they would have a chance to make up for the shortcomings they caused when lecturing in English.

\section{Facing a Problem with Answering the Students' Questions}

Facing a problem with answering the students' questions is also an anxiety-provoking factor. The participants would like to see the satisfaction on the learners' facial appearance. The situations in which the participants feel themselves insufficient to satisfy the learners' expectations with their questions give rise to a soaring anxiety. Participant $\mathrm{H}$ states that:

"When the learners are not satisfied with my answer to their open-ended questions, or when they find it insufficient, I feel anxious. Although I try to remove their suspicions for the response by restating it, I cannot manage to overcome the feeling of anxiety."

Participant B expresses that:

"Although I know the answer well, sometimes I can't manage to convey it to the students because of the inadequacy of my English proficiency."

As the answers above indicate, the academics face some problems with their answers to students' questions which may arise from either instant negative feedback provided by learners or the academics themselves who feel insufficient to convey what they know to the students in the target language.

\section{Being Unable to Understand What Is Uttered by the Learners}

Being unable to understand what is uttered by the learners is another source of anxiety. The participants express that the flow of information is interrupted when they need a further clarification. In this kind of situation, the participants feel as if they looked ridiculous. They think that the learners lose confidence in them because their authority is damaged in the classroom due to the fact that they cause the interruption of the flow of conversation. Participant B expresses that:

"Some learners' style of pronunciation complicates the issue of listening for me. Although I do not have a big problem with understanding what is spoken in general, I really have difficulty in understanding some learners' speech. Their 
Yildiz, Factors Causing English Speaking Anxiety on Non-English Major 401

fluency in speaking and disregard for the correctness of pronunciation typically disrupt the interaction among us."

Similarly, Participant A states that:

"Some of non-native speakers of English have really very bad pronunciation. The remaining of the class and I have difficulty in understanding their speech and it is very difficult to go on interaction with these students. This causes a kind of interruption in the flow of a lesson."

Based on the excerpts above, it can be inferred that the way the learners pronounce sounds might have a negative impact on the academics' speaking anxiety. When there is a lack of accuracy in the sound production, the flow of the lesson is interrupted.

\section{Academics' Self-Evaluation}

The facts that academics constantly feel the need to control each of their utterances during their speech and that they experience the fear of negative evaluation by students are discussed under this factor of academics' selfevaluation.

\section{Academics' Over-Monitoring Their Own Speech}

Academics' over-monitoring their own speech is one of the mostmentioned reasons of anxiety. The brain checks the speech for potential mistakes and individuals vary with monitoring their speech. Over-monitoring what is spoken causes some interruption in interaction, which decelerates and confuses the speaker. Participant G states that:

"At the beginning of my teaching experience in English, I was not sure of whether I conveyed the intended messages to the interlocutors. I was simultaneously teaching, translating the next sentence to be uttered in my mind, and checking the previous one for the accuracy. I cannot help thinking 'I wish I used 'this' instead of 'that' in the previous sentence', which confuses me a lot and escalates the anxiety. In the course of time, I unconsciously gave up thinking much about the discourse with the help of learners' participation to the lesson. Thus, I somehow managed to defeat anxiety."

Participant B expresses that:

"While speaking, I'm mostly busy with grammar rules. I feel as if I had to make sentences grammatically impeccant. This causes pressure on me as I have to both 
lecture and think about the next sentence I will utter. Because of this, I can't exactly focus on the lesson and learners."

The answers from participants $G$ and $B$ illustrate that non-English major academics are busy with checking the accuracy of both the previous sentences being uttered and the next ones to be potentially uttered. Besides, Participant G clearly expresses that stopping checking the accuracy of sentences helps him/her feel better.

\section{The Fear of Negative Evaluation}

The fear of negative evaluation is another anxiety-provoking situation. Teaching a group full of native speakers of English is a threatening act for the academics who are non-native speakers of English. They have some hesitations on whether their pronunciation and accent are acceptable to native speakers of English. Participant $\mathrm{C}$ states that:

"I feel myself under pressure while I am teaching to a class with native speakers of English. I feel as if they were continuously monitoring and criticizing my speaking skills. I always find myself checking these learners' facial expressions to be sure about their satisfaction."

Participant $\mathrm{G}$, who was typically over-monitoring his/her production at the beginning of his/her teaching process, underlines what $\mathrm{s} / \mathrm{he}$ has done to overcome the fear of negative evaluation.

"Instead of speaking slowly and being on the side of accuracy, I have encouraged myself to modify my mean length of utterance. I have tried to be more fluent. I have gained a speech rate which causes the learners make me stop to request clarification if needed."

The answers given above clearly illustrate that the learners who are native speakers of English seems to be one of the most influential reasons for the academics' fear of negative evaluation. Also, it can be inferred that the more the non-English major academics focus on the accuracy of their pronunciation and the way they speak, the more their anxiety level escalates. Participant G overcomes the fear of negative evaluation by increasing his/her speech rate and being more fluent. 
Yildiz, Factors Causing English Speaking Anxiety on Non-English Major 403

\section{Learner Factors}

Apart from the factors arising from the academics themselves, some kinds of students' behaviors and their inadequacies also lead to the academics' English speaking anxiety.

\section{Learner Behaviors}

Students' unwillingness to communicate during the lesson and their indifference to the lesson are the reasons for the academics' English speaking anxiety stemming from learner behaviors, as explained in the following.

\section{The Learners with an Impassive Look on Their Faces}

The learners with an impassive look on their face escalate the academics' anxiety level. The participants state that teaching is a kind of activity requiring a bidirectional flow of information. It necessitates a concomitant interaction between learners and teachers. Whether the messages sent by the teachers arrive at the learners are deduced from the learners' feedback. However, occasionally, some students do not react to these messages, which confuses the academics and puts them in a bit of dilemma concerning whether the input conveyed to the interlocutors is received or not.

\section{Learners' Lack of Interest to the Lesson}

Learners' lack of interest to the lesson also increases the academics' English speaking anxiety. Some learners behave as if they were obliged to be available in classroom. This leads the academics to think that both they and their lesson are unnecessary and useless. Participant D states that:

"Learners' indifference to the lesson makes me feel the tension. To avoid its negative effect on the lesson, I fix up the way I teach in the lesson. Transforming a theoretical course into an applied one works in general to attract the learners' attention to the lesson."

The issue seems more serious for Participant $\mathrm{C}$ who states that:

"Some students let me think that I am useless and persona non grata. They do not participate in activities and clearly show their displeasure."

As shown in the utterances of Participants D and C, students' attitudes towards the course and academics are one of the factors that cause the 
academics to experience anxiety. As Participant D mentions, instead of theoretical courses where one-way transfer of information is more intense, creating opportunities for students to apply what they have learned in the course can be a good step to engage the students in the lesson and reduce the tension experienced by non-English major academics.

\section{Learner Inadequacies}

In addition to learner behaviors, learners' inadequacies in four basic language skills and in the background knowledge of the course content contribute to the academics' English speaking anxiety.

\section{Learners' Lack of an Acceptable Level of Proficiency in English}

Learners' lack of an acceptable level of proficiency in English is also among the factors causing anxiety on non-English major academics. This makes the lesson turn into a one-way information transfer. However, the success of this one-way information transfer is always debatable. Participant $\mathrm{H}$ states that:

"I have difficulty in teaching some learners who have just basic level English proficiency. They cannot understand what I teach and consequently resist to both the lesson and me. I feel woefully inadequate for teaching them."

Students' limited knowledge of English causes them to fail in the course, which indirectly causes the academics to feel anxiety in the process.

\section{Learners' Academic Inadequacy}

Learners' academic inadequacy is another challenging factor causing anxiety on non-English major academics. The participants express that they feel so helpless against the learners' inadequate knowledge about the lesson. They frequently feel under a lot of pressure to teach some preliminary, extracurricular content to make learners ready for the current lesson content. Going beyond the scope of the current syllabus causes time pressure on the academics. They feel they have to be more rapid to complete the lesson in time. The academics prefer to ease the course content and their wording to cope with this situation. Participant A states that:

"If the learner group is not the intended population for the content of the current lesson as for their English proficiency and academic background, I revise the 
Yildiz, Factors Causing English Speaking Anxiety on Non-English Major 405

course content and its level of difficulty. I struggle for finding any common ground with learners to ensure the permanence of the lesson."

Participant $\mathrm{C}$ expresses that:

"To compensate learners' academic inadequacy, I try to teach lesson by slowly pronouncing each word as much as possible, emphasizing significant points again and again."

It can be inferred from the answers provided above that the academics develop a number of methods to deal with students' academic inadequacies. NonEnglish major academics try to cope with anxiety-provoking situations by both adapting the course content to students' academic adequacies and reducing the speed of their lecture delivery.

\section{Cultural Factors}

Cultural factors in multicultural classrooms consisting of learners from different cultures are another reason why non-English major academics feel English speaking anxiety.

\section{Cultural Differences (Failing to Comprehend Gestures and Cultural Jokes)}

Failing to comprehend gestures and cultural jokes is a kind of anxiety provoking situation. In multicultural classrooms, learners reflect the core of their own cultures, which is completely unfamiliar to other members of a class. In this kind of situation, the interaction between academics and learners is interrupted. Any feedback from interlocutors is received due to the unfamiliarity of input to them. Participant $\mathrm{H}$ states that:

"I have completed my graduate education in the U.S.A. Although I have spent plenty of time there, I frequently encounter with a brief interruption in interaction because of suffering difficulty in understanding learners' gestures or jokes. If a classroom consists of members from any other cultures, things get more complicated. In some cases, I cannot react to learners' gestures or jokes because I am totally unfamiliar to their culture. To fix the issue, I express clearly that I need further clarification for the parts causing the interaction to interrupt."

As Participant $\mathrm{H}$ stated above, culturally homogeneous classrooms in which academics and students are foreigners to one another culture could provoke anxiety on both students and academics. 
406 TEFLIN Journal, Volume 32, Number 2, July 2021

\section{Discussion}

Individual factors causing anxiety such as non-English major academics' English proficiency and their self-evaluation appear as the most frequently reported factors in this study. The literature also reflects similar results. For example, being unable to answer questions is not an anxiety-provoking factor just for the academics. EFL learners also get anxious if they are unable to answer the teachers' questions (Shabani, 2012). Similarly, teachers' language proficiency is among the factors causing anxiety in Klanrit and Sroinam (2012). In the present study, almost all of the participants clearly state that teaching in their native language, no doubt, creates a difference. If they had a chance to use their mother tongue in situations where their English language skills were insufficient, this could lower their anxiety levels. Although they try to overcome some expected problems with the help of a detailed preparation before the lesson, there are always unexpected questions or situations causing anxiety. They believe that summarizing the lesson in their native language would let them compensate their inadequacy arising from their foreign language proficiency in teaching process.

As for the academics' self-evaluation, it can be inferred that the brain is busy with over-monitoring the linguistic output. Based on studies, this happens not only with non-English major academics. The pre-service English teachers in Yoon's (2012) study, for example, feel lack of confidence in using English as a medium of instruction. In a similar way, EFL learners also experience the fear of negative evaluation (Hashemi, 2011; Öztürk \& Gürbüz, 2014; Riasati, 2011; Shabani, 2012; Tsiplakides \& Keramida, 2009). It can be concluded that academics also have some self-evaluation problems as both pre-service and inservice teachers and EFL learners. Gaining experience in the field is not enough for teachers or academics to get rid of anxiety based on self-evaluation.

In addition, learners' behaviors and inadequacies are one of the biggest obstacles which affect the interaction among learners and academics. If the academics are unable to convey their messages to the learners, the classroom setting does not serve a purpose, which makes academics feel the tension. Variables related to academics are not enough to account for their speaking anxiety. The factors concerning learners also constitute a major explanation for the academics' English speaking anxiety. Similar to the present findings, in Kongchan and Singhasiri (2008), although teachers generally do not feel 
anxious while teaching in English, they are anxious about learners' not understanding them effectively.

Furthermore, learners' low English proficiency does not cause only academics to feel anxiety. As Semmar (2010) indicates, university students are also anxious due to their low English proficiency level. Similar to Semmar (2010), Alemi et al. (2011) find that anxiety and language proficiency are negatively correlated. The more language proficiency the learners have, the higher willingness to communicate they show, and vice versa. Thus, the learners that the participants teach might also experience anxiety themselves, which causes them to be unwilling to communicate. This, in turn, hinders the flow of information between the academics and learners, causing anxiety on the academics.

Cultural differences are a kind of anxiety-provoking factors also for EFL learners (Hashemi, 2011), teachers and practitioners (Tanveer, 2007). Presumably, the learners in the classroom also complain about the same cultural differences the academics highlight (Takkaç Tulgar, 2018). In a similar way to the culture-related results of the present study, even though the target language is not English but Turkish in Takkaç Tulgar (2018), foreign learners of Turkish also experience speaking anxiety because of cultural differences. They mention that they are afraid of talking to someone in a culturally inappropriate way. It is very likely that an interruption in interaction will occur between learners and academics because of some unshared cultural knowledge. Unfamiliarity with the cultural features of the remaining class creates a barrier to a mutual flow of information.

\section{CONCLUSIONS}

The aim of the present study is to investigate the sources of English speaking anxiety that non-English major academics experience while using English as a medium of instruction. The results demonstrate that the reasons causing anxiety on academics can be grouped under five main themes as academics' English proficiency, academics' self-evaluation, learner behaviors, learner inadequacies, and cultural differences.

A few suggestions can be made to non-English major academics in order to offer a solution to overcome English speaking anxiety. Individual factors are related to the incremental nature of foreign language learning process. Gradual 
increase in knowledge of the foreign language and the transfer of this knowledge to productive language skills lead to a decrease in anxiety level. Regular practice of productive foreign language skills such as writing and speaking will help activate one's passive language knowledge. The more actively academics use their productive language knowledge, the less anxiety they experience. Therefore, it should be emphasized that language learning is a process and that this process should continue uninterrupted.

Regarding learner factors, professional development of academics can be mentioned. Professional development is also dynamic, as is the foreign language learning process. Although the academics have massive knowledge about classroom management and communication with learners, the importance of following current developments and keeping up with them cannot be denied. It should be kept in mind that over the years, student behaviors and, accordingly, the classroom environment change. In order to keep up with the times, professional development activities should be utilized at the maximum level.

As for cultural factors, it should be underlined that both academics and students need time to get to know each other's cultures. Especially in multicultural classrooms with students of different nationalities, raising awareness about possible problems that may arise due to cultural differences will contribute positively to the education environment. The positive atmosphere in the classroom also has a significant effect on reducing the speaking anxiety levels of not only academics but also students.

Some suggestions can be made to potential researchers who are considering doing research on the same subject. The present study was a qualitative study to get a deep insight into the effects of anxiety on non-English major academics. If prospective researchers have the chance to reach a large number of academics who have experienced teaching in English, they may consider collecting data using quantitative methods. Participants found to be outliers in line with the analysis of quantitative data may be invited to further qualitative data collection process. Thus, further data can be obtained from both participants with very low anxiety levels and the ones with very high anxiety levels. 
Yildiz, Factors Causing English Speaking Anxiety on Non-English Major 409

\section{REFERENCES}

Alemi, M., Daftarifard, P., \& Pashmforoosh, R. (2011). The impact of language anxiety and language proficiency on WTC in EFL context. Cross-Cultural Communication, 7(3), 150-166. http://dx.doi.org/10.3968/j.ccc.1923670020110703.152

Botes, E., Dewaele, J., \& Greiff, S. (2020). The foreign language classroom anxiety scale and academic achievement: An overview of the prevailing literature and a meta-analysis. Journal for the Psychology of Language Learning, 2, 26-56. https://jpll.org/index.php/journal/article/view/botesetal

Çağatay, S. (2015). Examining EFL students' foreign language speaking anxiety: The case at a Turkish state university. Procedia - Social and Behavioral Sciences, 199, 648-656. https://doi.org/10.1016/ j.sbspro.2015.07.594

Castillejo, S. P. (2019). The role of foreign language anxiety on L2 utterance fluency during a final exam. Language Testing, 36(3), 327-345. https://doi.org/10.1177/0265532218777783

Creswell, J. W. (2012). Educational research: Planning, conducting and evaluating quantitative and qualitative research $\left(4^{\text {th }}\right.$ ed.). Pearson Education.

Cui, J. (2011). Research on high school students' English learning anxiety. Journal of Language Teaching and Research, 2(4), 875-880. https://doi.org/10.4304/jltr.2.4.875-880

Dolean, D. D. (2016). The effects of teaching songs during foreign language classes on students' foreign language anxiety. Language Testing, 20(5), 638-653. https://doi.org/10.1177/1362168815606151

Dörnyei, Z. (2005). The psychology of the language learner: Individual differences in second language acquisition. Routledge.

Ferdous, F. (2012). A case study of first-year non-English undergraduate students' English learning anxiety in Bangladesh. Journal of Education and Practice, 3(9), 1-12. https://iiste.org/Journals/index.php/ $\mathrm{JEP} /$ article/view/2278/2281

Han, T., Tanriöver, A. S., \& Şahan, Ö. (2016). EFL students' and teachers' attitudes toward foreign language speaking anxiety: A look at NESTs and Non-NESTs. International Education Studies, 9(3), 1-11. https://doi.org/10.5539/ies.v9n3p1 
Han, T., Gözpınar, H., Akyüz, M. (2020). Examining non-native English speaking academics' communication apprehension in international academic meetings: A Turkish context. Inonu University Journal of the Faculty of Education, 21(2), 880-893. https://doi.org/10.17679/ inuefd.533100

Hashemi, M. (2011). Language stress and anxiety among the English language learners. Procedia - Social and Behavioral Sciences, 30, 1811-1816. https://doi.org/10.1016/j.sbspro.2011.10.349

Horwitz, E. K., Horwitz, M. B., \& Cope, J. (1986). Foreign language classroom anxiety. The Modern Language Journal, 70(2), 125-132. https://doi.org/10.2307/327317

Jin Y., Zhang L. J. \& MacIntyre P. D. (2020). Contracting students for the reduction of foreign language classroom anxiety: An approach nurturing positive mindsets and behaviors. Frontiers in Psychology, 11, 1-11. https://doi.org/10.3389/fpsyg.2020.01471

Kao, P., \& Craigie, P. (2013). Coping strategies of Taiwanese university students as predictors of English language learner anxiety. Social Behavior and Personality, 41(3), 411-420. https://doi.org/10.2224/ sbp.2013.41.3.411

Klanrit, P., \& Sroinam, R. (2012). EFL teacher's anxiety in using English in teaching in the language classroom. International Journal of Social Science and Humanity, 2(6), 493-496. https://doi.org/10.7763/IJSSH.2012.V2.154

Kongchan, C., \& Singhasiri, W. (2008). Teachers' anxiety about using L2 in EFL classrooms. Proceedings of the 16th Annual Korea TESOL International Conference: Responding to a Changing World. Seoul, Korea. 25-26 October 2008, 145-149. https://arts.kmutt.ac.th/crs/downloads/article_repository/20150521114312teachers-anxiety-about-using-12-in-efl-classrooms.pdf

Kralova, Z. \& Tirpakova, A. (2019). Nonnative EFL teachers' speaking anxiety: Post-communist country context. Sage Open, 9(2), 1-13. https://doi.org/10.1177/2158244019846698

Lu, Z., \& Liu, M. (2011). Foreign language anxiety and strategy use: A study with Chinese undergraduate EFL learners. Journal of Language Teaching and Research, 2(6), 1298-1305. https://doi.org/10.4304/JLTR.2.6.12981305 
Yildiz, Factors Causing English Speaking Anxiety on Non-English Major 411

Lucas, R. I., Miraflores, E., \& Go, D. (2011). English language learning anxiety among foreign language learners in the Philippines. Philippine ESL Journal, 7, 94-119. https://www.researchgate.net/publication/ 256495249_English_Language_Learning_Anxiety_among_Foreign_Lang uage_Learners_in_the_Philippines

MacIntyre, P., \& Gardner, R. (1991). Methods and results in the study of anxiety and language learning: A review of the literature. Language Learning, 4l(1), 85-117. https://doi.org/10.1111/j.14671770.1991.tb00677.x

MacIntyre, P. D., \& Gardner, R. C. (1994). The subtle effects of language anxiety on cognitive processing in the second language. Language Learning, 44(2), 283-305. https://doi.org/10.1111/j.14671770.1994.tb01103.x

Matsuda, S., \& Gobel, P. (2004). Anxiety and predictors of performance in the foreign language classroom. System, 32(1), 21-36. https://doi.org/10.1016/j.system.2003.08.002

Maykut, P., \& Morehouse, R. (2005). Beginning qualitative research: A philosophic and practical guide. The Falmer Press e-library.

Miles, M. B., \& Huberman, A. M. (1994). Qualitative data analysis: An expanded sourcebook ( $2^{\text {nd }}$ ed.). Sage Publications.

Öztürk, G., \& Gürbüz, N. (2014). Speaking anxiety among Turkish EFL learners: The case at a state university. Journal of Language and Linguistic Studies, 10(1), 1-17. http://www.jlls.org/index.php/jlls/ article/view/178/165

Riasati, M. J. (2011). Language learning anxiety from EFL learners' perspective. Middle-East Journal of Scientific Research, 7(6), 907-914. https://www.idosi.org/mejsr/mejsr7(6)11/13.pdf

Semmar, Y. (2010). First year university students and language anxiety: Insights into the English version of the foreign language classroom anxiety scale. The International Journal of Learning, 17(1), 81-93. https://doi.org/10.18848/1447-9494/CGP/v17i01/46805

Shabani, M. B. (2012). Levels and sources of language anxiety and fear of negative evaluation among Iranian EFL learners. Theory and Practice in Language Studies, 2(11), 2378-2383. https://doi.org/10.4304/TPLS. 2.11.2378-2383 
Spielberger, C. D. (1972). Current trends in theory and research on anxiety. In C. D. Spielberger (Ed.), Anxiety: Current trends in theory and research (Vol. 1, pp. 3-19). Academic Press.

Takkaç Tulgar, A. (2018). Speaking anxiety of foreign learners of Turkish in target context. International Online Journal of Education and Teaching (IOJET), 5(2),313-332. https://files.eric.ed.gov/fulltext/EJ1258901.pdf

Tanveer, M. (2007). Investigation of the factors that cause language anxiety for ESL/EFL learners in learning speaking skills and the influence it casts on communication in the target language. (Master's Thesis, University of Glasgow, Scotland). http://dx.doi.org/10.13140/ RG.2.1.1995.1129

Toth, Z. (2011). Foreign language anxiety and advanced EFL learners: An interview study. Working Papers in Language Pedagogy, 5, 39-57. http://langped.elte.hu/WoPaLParticles/W5Toth.pdf

Tsiplakides, I. \& Keramida, A. (2009). Helping students overcome foreign language speaking anxiety in the English classroom: Theoretical issues and practical recommendations. International Education Studies, 2(4), 3944 https://doi.org/10.5539/ies.v2n4p39.

Williams, K., \& Andrade, M. (2008). Foreign language learning anxiety in Japanese EFL university classes: Causes, coping, and locus of control. Electronic Journal of Foreign Language Teaching, 5(2), 181-191. https://e-flt.nus.edu.sg/wpcontent/uploads/2020/09/v5n22008/williams.pdf

Woodrow, L. (2006). Anxiety and speaking English as a second language. RELC Journal, 37(3), 308-328. https://doi.org/10.1177/0033688206071315

Yentürk, C., \& Dağdeviren-Kırmızı, G. (2020). Native or non-native instructors? A case study on foreign language speaking anxiety in EFL classroom. Journal of Language and Linguistic Studies, 16(4), 1939-1951. https://doi.org/10.17263/j1ls.851025

Yoon, T. (2012). Teaching English though English: Exploring anxiety in nonnative pre-service ESL teachers. Theory and Practice in Language Studies, 2(6), 1099- 1107. https://doi.org/10.4304/tpls.2.6.1099-1107 